\title{
DESFOLHAMENTO E MORTE PROGRESSIVA DE RAMOS DE Ficus microcarpa (MORACEAE) EM BELO HORIZONTE, MINAS GERAIS, BRASIL
}

Mívia Rosa de Medeiros Vichiato; Marcelo Vichiato²; Percílio Wander da Silva²; Cássia Lafetá do Couto Leonardo de Souza Pereira ${ }^{2}$; Milton Luiz da Paz Lima ${ }^{3}$ e Ernesto Prado ${ }^{4}$

\section{RESUMO}

Fatores bióticos a abióticos são importantes agentes de declínio de árvores de interesse na arborização urbana. Este trabalho objetivou a investigação dos problemas fitossanitários (desfolhamento e morte progressiva de ramos) apresentados por Ficus microcarpa (Moraceae) localizados no canteiro central da Avenida Bernardo Monteiro, em Belo Horizonte, Minas Gerais, Brasil. Análises entomológicas e amostras de plantas infectadas revelaram que os agentes causadores da queda de folhas e da morte progressiva de ramos dos Ficus microcarpa são, respectivamente, a mosca-branca-dos-fícus - Singhiella simplex (Hemiptera: Aleyrodidae) e o fungo Lasiodiplodia theobromae (Pat.) Griffon \& Maubl. (= Botryodiplodia theobromae Pat.).

Palavras-chave: Arborização urbana, entomologia, fitopatologia, Lasiodiplodia theobroma, Singhiella simplex.

\section{DEFOLIATION AND DIEBACK OF TWIGS ON Ficus microcarpa L. TREES IN BELO HORIZONTE, MINAS GERAIS, BRAZIL}

\section{ABSTRACT}

Biotic and abiotic factors are the important agents of tree decline in the urban forestry. This work aimed to investigate phytosanitary problems (fall leaves and progressive death of branches) that affect arboreal specimens of F. microcarpa on central region of Belo Horizonte. Entomological analysis and samples of infected plants showed that the causal agents of F. microcarpa problems are, respectively, the ficus whitefly Singhiella sp. (Hemiptera: Aleyrodidae) and the fungi Lasiodiplodia theobromae (Pat.) Griffon \& M Griffon \&Maubl. (= Botryodiplodia theobromae Pat.).

Key words: Urban forestry, entomology, phitopathology, Lasiodiplodia theobroma, Singhiella simplex.

\footnotetext{
${ }^{1}$ Bióloga Doutora em Fitotecnia. Secretaria Municipal de Meio Ambiente - SMMA/PBH.mivia@ig.com.br

2 Engenheiros Agrônomos. SMMA/PBH

${ }^{3}$ Engenheiro Agrônomo, Prof. Dr. do Instituto Federal Goiano, Curso de Agronomia.

${ }^{4}$ Pesquisador, Embrapa Café/EPAMIG Sul de Minas

${ }^{5}$ recebido em 08.07.2013 e aceito para publicação em 05.11.2012
} 
Ficus microcarpa L.f. e Ficus benjamina L. (Moraceae) são espécies florestais comuns na arborização brasileira e, por sua copa exuberante e hábito de desenvolvimento frondoso, representam presença marcante na paisagem.

Entretanto, o porte expressivo e as raízes agressivas dessas espécies podem causar transtornos, razão pela qual são recomendadas somente para grandes áreas, onde não possam afetar edificações e tubulações subterrâneas.

Em Belo Horizonte, Minas Gerais, Brasil, árvores destas espécies vêm apresentando sintomas como queda expressiva de folhas e morte progressiva de ramos, comprometendo a densa e verdejante copa, típica das espécies que, normalmente, têm hábito perenifólio. Outros sintomas constatados têm sido variáveis, como a clorose foliar e a incidência de mosca-branca (Hemiptera: Aleyrodidae), thrips (Ordem Thysanoptera) ou cochonilhas (Dactylopiidae).

A doença "morte progressiva" é caracterizada pela necrose e seca dos tecidos afetados, e avança progressivamente do ápice aos galhos grossos e troncos, resultando em queda da folhagem, definhamento e morte do hospedeiro (ZABOLIM et al., 2002; LINS et al. 2010).

Em 2003 a morte progressiva em ramos de espécimes de F. benjamina em Brasília (Distrito Federal) e Uberlândia (Minas Gerais), Brasil foi devida ao cancro no tronco, seguido da seca lateral expansiva de ramos pela interrupção da vascularização. Estes espécimes apresentavam cancro no tronco que avançava para uma seca lateral expansiva de ramos, devida à interrupção da vascularização. Esta doença foi causada por Phomopsis cinerescens Trav (Diaporthales: Diaporthaceae), que foi, também, relatada em plantas de $F$. benjamina nos Estados Unidos da América (EUA) e Canadá, confirmando a gravidade e a importância da doença para esta espécie (PAZLIMA et al. 2005).

Figueiras (Ficus carica L.) em Fortaleza, Ceará, Brasil apresentaram sintomas de seca-descendente e o fungo Lasiodiplodia theobromae era o agente causal da doença (FREIRE et al., 2009).

Os fungos $L$. theobromae e Phomopsis sp. (Diaporthales: Diaporthaceae) são os mais frequentes agentes causais de secas de ramos e troncos, murchas e consequente abscisão de folhas que afetam espécies de Ficus. (OLIVEIRA et al., 2010).

A morte súbita de ramos de $F$. benjamina foi relatada no Rio de Janeiro e São Paulo, Brasil. A mosca branca (Bemisia tabaci Gennadius, 1889; Hemiptera: Aleyrodidae) disseminou a doença em São Paulo (CASTRO, 2011). A desfolha intensa em F. benjamina em São Paulo foi associada com a infestação por mosca-branca-do-fícus (Singhiella simplex Singh, 1931; Hemiptera: Aleyrodidae) (VELASCO et al., 2011).

Em agosto de 2007 na Flórida (EUA), foram registrados severos danos por mosca-branca-dofícus (Singhiella simplex Singh, 1931) em várias espécies de Ficus (F. altissima, F. aurea, F. benjamina, $F$. microcarpa, $F$. lyrata e $F$. maclellandii) utilizadas na arborização pública e em cercas vivas, ocasionando desfolhamento intenso e morte das plantas.

Essa praga foi relatada em Ilhas Cayman, Jamaica e Porto Rico. No Brasil, o primeiro relato de S. simplex foi em agosto de 2009 no Rio de Janeiro e, em 2010, em F. benjamina em São Paulo (JESUS et al., 2010; VELASCO et al., 2011).

O objetivo desse trabalho foi avaliar a fitopatologia de 53 espécimes arbóreos de F. microcarpa no canteiro central da Avenida Bernardo Monteiro em Belo Horizonte, Minas Gerais, Brasil com queda expressiva de folhas e morte progressiva de ramos.

\section{MATERIAL E MÉTODOS}

Cento e cinquenta folhas e cinquenta ramos com sintomas de morte progressiva de ramos foram coletadas aleatoriamente nas plantas de $F$. microcarpa no canteiro central da Avenida Bernardo Monteiro em Belo Horizonte, Minas Gerais, Brasil, situada a $19^{\circ} 48^{\prime}$ 57" Sul de latitude sul e $43^{\circ} 57^{\prime} 15^{\prime \prime}$ de longitude oeste. As amostras foram mantidas em sacos plásticos e enviadas ao Laboratório de Microbiologia e Fitopatologia do Instituto Federal Goiano, campus Urutaí, em Urutaí, Goiás, Brasil. 
As amostras foram analisadas em duas etapas: primeiro foi realizado exame dos tecidos externos de folhas e ramos e, segundo, os ramos foram dissecados e analisados em microscópio estereoscópio. O escurecimento vascular do tecido do caule foi, também, observado. Os fragmentos de tecidos internos e necrosados obtidos foram submetidos à assepsia com sequência de álcool [70\%] (3'), hipoclorito de sódio (HCLO) [0,3\%] (3') e água destilada esterilizada (3X). Em seguida, esses fragmentos foram secos e depositados no centro de placas de Petri contendo ágar-água [2\%] (AA). As placas foram incubadas à temperatura de 25 a $28^{\circ} \mathrm{C}$, no escuro, durante 48 horas. Fragmentos de micélio retirados do meio AA foram repicados para meio batata-dextrose-ágar (BDA). Os isolados purificados foram utilizados no teste de patogenicidade. As placas purificadas permaneceram incubadas em câmara de crescimento à temperatura de $25 \mathrm{a} 28^{\circ} \mathrm{C}$, no escuro, por sete dias.

Os fungos foram identificados pelo exame direto e no isolamento em meio de cultura em microscópio estereoscópico utilizado para preparo de lâminas semipermanentes (fixador lactofenol contendo azul de metileno) e analisados em microscópio ótico.

Para a análise entomológica, espécies adultas e imaturas e ovos foram coletados nos troncos, ramos e folhas dos fícus e encaminhados ao Laboratório de Controle Biológico da Empresa de pesquisa Agropecuária de Minas Gerais - Centro Tecnológico do Sul de Mias (EPAMIG/CTSM) EcoCentro, em Lavras (MG), Minas Gerais, Brasil, onde foram realizadas limpeza e separação dos insetos. A identificação dos insetos associados ao ataque da praga foi realizada em nível de espécie.

\section{RESULTADOS E DISCUSSÃO}

\section{Exame direto da amostra}

$\mathrm{Na}$ parte aérea dos espécimes arbóreos de $F$. microcarpa analisados, foram observados fungos (fumagina) e insetos como thrips, cochonilhas e mosca-branca, esta com infestação ativa.

$\mathrm{Na}$ superfície das estacas, ramos e folhas foram detectados os seguintes gêneros fúngicos: Bipolaris sp., Cladosporium sp., Curvularia sp., Humicola sp., Mucor sp. e Torula sp. e a espécie Clamydomyces palmarum (Figura 1).

Os gêneros dos fungos identificados na superfície do material biológico encaminhado são saprobiontes associados ou endofíticos, que colonizam sistemicamente o interior das plantas sem causar danos, ou eventualmente, apresentar interação parasitária (CARDOSO et al., 2009).

\section{Isolamento do tecido}

Lasiodiplodia theobromae, forma anemórfica de Botryosphaeria dothidea (Moung. Ex Fr.), foi o agente causal da morte progressiva de ramos de $F$. microcarpa analisados. Em placa de Petri este fungo apresentou micélio escuro e acinzentado, que aos 10 dias mostrou frutificações abundantes e rígidas de picnídios estromáticos (Figura 2).

Lasiodiplodia theobromae também foi relatado em ramos e tronco de plantas de Ficus carica (FREIRE et al., 2004) e F. benjamina (PAZ-LIMA et al., 2005)

Este estudo comprovou, após o teste de patogenicidade, que $L$. theobromae é agente causal da seca de ramos e tronco de F. microcarpa. 


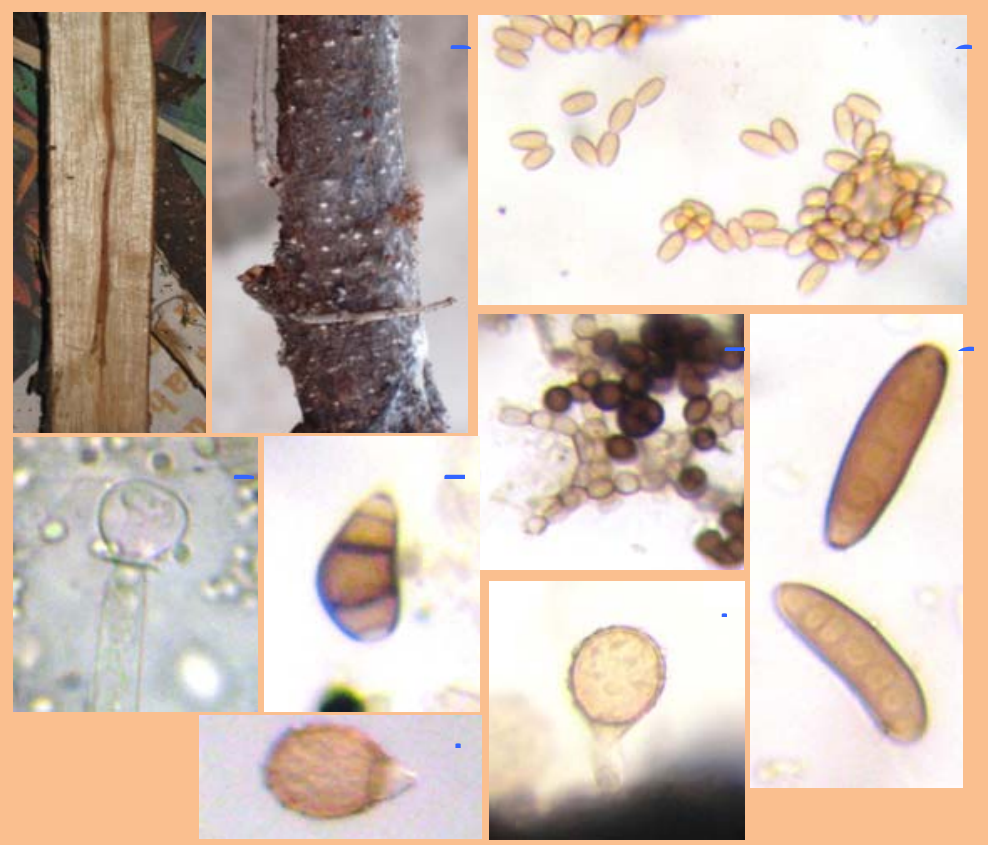

Figura 1. Fungos identificados nas amostras de Ficus microcarpa L.f. (Moraceae) oriundas de Belo Horizonte, Minas Gerais, Brasil. A Sintoma de lesão necrótica no tecido vascular; B - Pulverulência escurecida de fungos decompositores e saprobiontes na superfície dos materiais biológicos amostrados; C - Hifomiceto dematiáceo decompositor e secundário (pulverulência marrom da foto B); D - Esporângio e esporangióforo de Mucor sp.; E - Conídio de Curvularia sp.; F - Hifas, micélios e conídios de Torula sp.; G - conídios de Bipolaris sp.; H e I - Conídios de Clamydomyces palmarum.

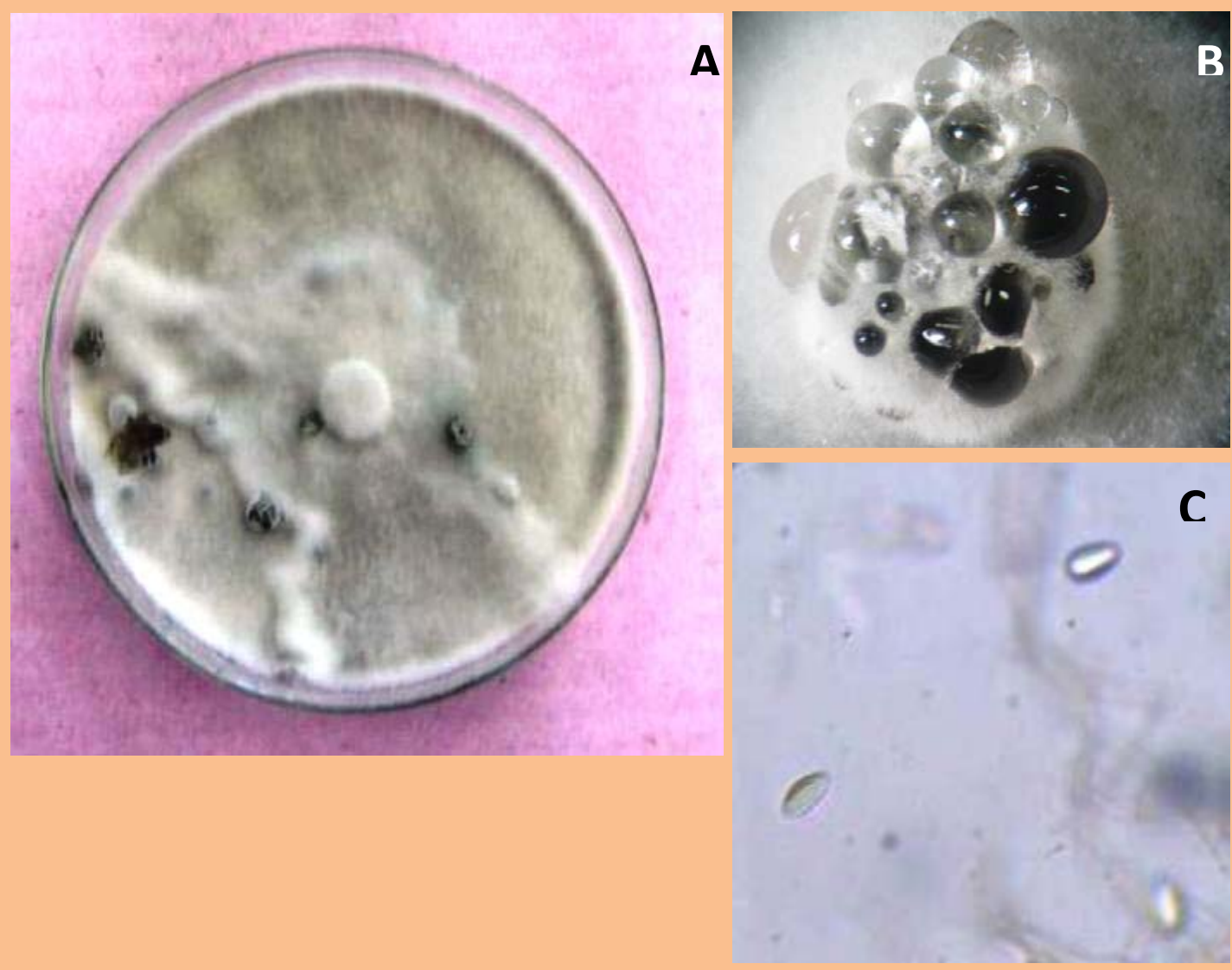

Figura 2. Aspectos gerais de Lasiodiplodia theobromae (Pat.) Griffon \& Maubl. (Botryosphaeriales: Botryosphaeriaceae), agente etiológico da seca de Ficus microcarpa L.f. (Moraceae) em Belo Horizonte, Minas Gerais, Brasil. A - Cultura micelial de coloração branco acinzentado inicialmente produzindo tecido estromático; B - Tecido estromático picnidial exsudando gotículas condensadas de água e/ou mucilagem (massa de conídos); C - Conídios hialinos imaturos. 


\subsection{Sobre o fungo Lasiodiplodia theobromae}

O fungo L. theobromae é típico de regiões tropicais e subtropicais, sendo patogênico a numerosas espécies vegetais como fícus (Ficus benjamina e F. microcarpa), abacateiro (Persea gratissima), bananeira (Musa paradisiaca), cacaueiro (Theobroma cacao), cafeeiro (Coffea arabica), cajueiro (Anacardium occidentale), caquizeiro (Diospyros kaki), citros (Citrus spp.), coqueiro (Cocus nucifera), cupuaçuzeiro (Theobroma grandiflorum), eucalipto (Eucaliptus spp.), goiabeira (Psidium guajava), macieira (Malus domestica), mamoeiro (Carica papaya), mangueira (Mangifera indica), maracujazeiro (Passiflora edulis), noz macadâmia (Macadamia integrifolia), pequizeiro (Caryocar brasiliense), pimenta-doreino (Piper nigrum), ulmeiro-siberiano (Ulmus pumila) e videira (Vitis vinifera) (RODRIGUES, 2003; PEREIRA, 2009).

O processo de infecção é induzido por estresses ambientais e deficiências nutricionais que reduzem a ação dos mecanismos de defesa do hospedeiro, favorecendo a infecção em plantas estressadas (MOHALI et al., 2005; CARDOSO et al. 2009; PEREIRA, 2009).

Após a planta ser infectada, o fungo pode permanecer nos tecidos vasculares até o declínio da mesma. A disseminação ocorre por ventos e instrumentos de poda, e a penetração na planta ocorre por aberturas naturais ou ferimentos. Estresse hídrico ou o excesso de água, deficiência de cálcio e falta de proteção aos ramos podados constituem portas de entrada para o fungo na planta. Em geral, L. theobromae prefere plantas sob estresse e com ferimentos naturais ou provocados pelo homem durante as práticas culturais (ZAMBOLIM et al., 2002; MOHALI et al., 2005; CARDOSO et al., 2009; PEREIRA, 2009).

\subsection{Controle químico de Lasiodiplodia theobromae}

Os fícus amostrados são plantas frequentemente submetidas a podas, uma vez que seu porte expressivo e suas raízes agressivas podem entrar em conflito com os equipamentos urbanos em seu entorno (calçamentos, calhas, encanamentos, fiações elétricas, muros, postes de iluminação etc.). Essas operações contribuem para o estado de estresse dessas plantas, predispondo-as a declínio do fuste.

Não há na literatura ou registrado no Ministério da Agricultura, Pecuária e Abastecimento (MAPA) informações sobre um fungicida potencialmente eficiente no controle por terapia e/ou proteção de $L$. theobromae (AMORIN et al., 2011). O que se tem verificado são testes de fungicidas in vitro, que se constituem numa fase preliminar da seleção de produtos químicos a serem utilizados in vivo (RODRIGUES, 2003; PEREIRA, 2009).

Em coqueiros (Cocos nucifera), a aplicação anual de pulverizações da mistura de Benomyl ${ }^{\circledR}$ a $0,1 \%$ i.a. (produto atualmente retirado do mercado, similar tiofanato metílico) e Carbendazin ${ }^{\circledR}$ a $0,1 \%$ i.a., com intervalos de 15 dias, totalizando 8 aplicações, não foram eficientes no controle da doença (RAM, 1993).

O extrato aquoso de juá (Ziziphus joazeiro) e alho (Allium sativu) foi eficiente 'in vitro' no controle alternativo de L. theobromae (LIMA et al., 1993; FEITOSA et al., 2000).

Visando a desinfecção das sementes gravioleira (Annona muricata) e da ateira (A. squamosa) contra L. theobromae, Santos et al. (2000) testaram 12 tratamentos químicos e constataram que apenas o Benomyl $\AA^{\circledR}$ foi eficaz no controle desse fungo.

\subsection{Manejo integrado de Lasiodiplodia theobromae}

Lasiodiplodia theobromae prefere colonizar plantas sob estresse e aquelas com ferimentos naturais ou provocados pelo homem durante as práticas culturais. Isto sugere que plantas adubadas e irrigadas, sem períodos de estresses prolongados e com tratos culturais podem desfavorecer a doença. Plantas afetadas devem ser eliminadas e a irrigação por aspersão deve ser evitada, como forma de reduzir o inóculo e a dispersão da doença. Insetos como psilídeos ou thrips, que provocam ferimentos ao picar a planta, favorecem a disseminação da doença (DOMINGUES et al., 2011). O thrips lacerdinha, Gynaikothrips ficorum Marchal (Thysanoptera: Phloeothrips) infesta espécies de Ficus (DUARTE, 2007; PINHO et al., 2007; SILVA et al. 2007).

As medidas de controle devem ser integradas, envolvendo: 
a) Vistorias nas áreas em análise para se verificar a presença de manchas e desidratação de ramos, morte dos ramos ponteiros, galhos podados que não foram eliminados nas podas de limpeza;

b) $\mathrm{Na}$ arborização urbana, utilizar somente mudas sadias, sem sinal de estresse, lesão ou doença;

c) Evitar submeter plantas a estresse hídrico ou nutricional prolongado;

d) Podar e eliminar sistematicamente os ramos, galhos e ponteiros afetados ou secos que possam favorecer a sobrevivência do fungo;

e) Retirar imediatamente todo o tecido podado e destruí-lo pela queima;

h) Desinfetar com as ferramentas de poda, após seu uso, com solução de água sanitária (hipoclorito de sódio) a $2 \%$;

i) Controlar as coleobrocas ou outros insetos que possam causar nas árvores ferimentos que sirvam de porta de entrada para o fungo.

\subsection{Convivência com Lasiodiplodia theobromae}

Como as práticas de manejo descritas anteriormente de difícil aplicação nas árvores urbanas, para a convivência com o fungo, as medidas de proteção das árvores não infectadas compreendem os seguintes pontos:

a) Evitar estresse hídrico pela falta ou excesso de água, uma vez que esta condição predispõe as plantas ao fungo;

b) Evitar ferimentos nas raízes e a técnica de torção de ramos pela poda;

c) Desinfestar as ferramentas de poda com hipoclorito de sódio (água sanitária) diluído em água, na proporção de 1:3, após a poda de cada planta;

d) Manter a superfície do solo sem restos da cultura, mesmo que sadios, uma vez que esse fungo coloniza, também, os tecidos vegetais no solo, mantendo-se vivo, mesmo quando estes se decompõem;

e) Fazer inspeções periódicas nas áreas verdes, para verificar sintomas da doença e providenciar a eliminação do órgão infectado, em tempo hábil.

\section{Análise entomológica}

$\mathrm{O}$ agente causal da queda expressiva de folhas foi a mosca-branca-dos-fícus, Singhella simplex (Hemiptera: Aleyrodidae) - Figura 3.

Esses resultados são condizentes com o trabalho de Jesus et al. (2010) e Velasco et al. (2011) que constataram que Singhiella simplex (Singh, 1931) era o agente causal da desfolha de Ficus benjamina no Rio de Janeiro e São Paulo (Brasil), respectivamente.

Os Ficus microcarpa infestados por Singhella simplex apresentavam desfolha e seca dos ramos apicais. Isso porque a mosca-branca é inseto sugador de seiva que inocula substâncias toxicogênicas nas folhas, provocando rápido amarelecimento e queda prematura das mesmas (JESUS et al., 2010)

Velasco et al. (2011) ressaltaram que a moscabranca-dos-fícus e os fungos associados desenvolvem-se bem em climas distintos, havendo grande possibilidade de disseminação por diversas cidades onde espécies do gênero Ficus estão plantadas.

Todos os 54 espécimes de Ficus microcarpa analisados apresentaram sintomas de ataque e a presença de $S$. simplex. Este resultado é preocupante porque os espécimes considerados são árvores longevas, de grande valor ornamental e estético, apresentam relações históricas, sociais e afetivas com a população belo-horizontina e, por isso, são referências paisagísticas insubstituíveis. 

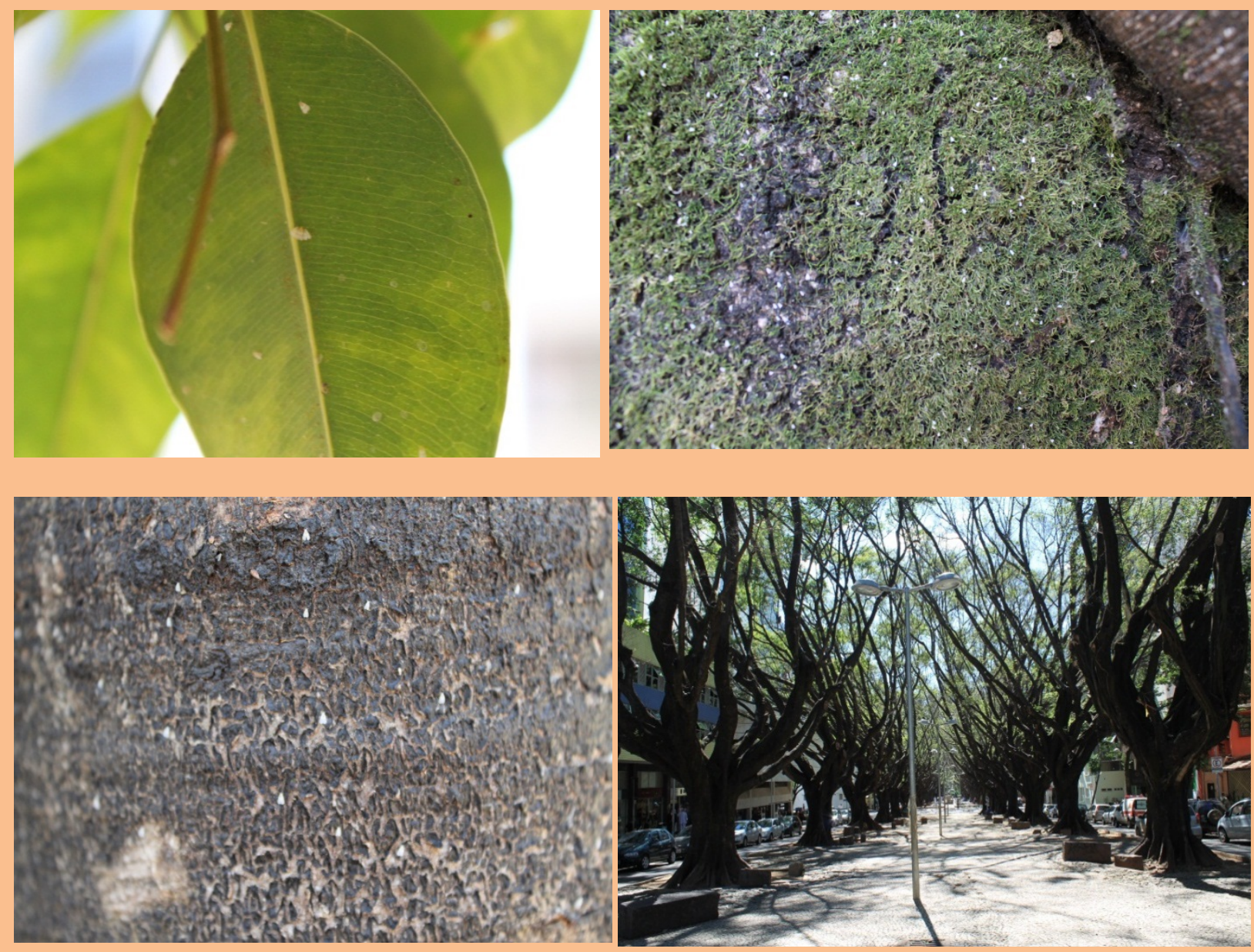

Figura 3 - Aspectos gerais de infestação ativa em folhas e caules de Ficus benjamina L.f. (Moraceae) por mosca-branca-dos-fícus, Singhella simplex (Hemiptera: Aleyrodidae).

\subsection{Sobre a mosca Singhella simplex (Hemiptera: Aleyrodidae)}

Singhella simplex é um pequeno inseto que se alimenta de plantas cultivadas ornamentais e invasoras, causando danos diretos ao vegetal. Os adultos medem de 1 a $2 \mathrm{~mm}$ de comprimento e 0,36 a $0,51 \mathrm{~mm}$ de largura e a fêmea maior que o macho e as asas cobertas com substância pulverulenta branca (JESUS et al., 2010).

Ao sugar a seiva das plantas hospedeiras, quando se alimentam, podem provocar alterações no desenvolvimento vegetativo e reprodutivo da planta, sendo que altas densidades populacionais podem levá-la à morte. A substância açucarada excretada pelos insetos induz o crescimento de fungos saprófitas (fumagina) sobre ramos e folhas, prejudicando o processo de fotossíntese.

Em 2007 S. simplex foi relatada pela primeira vez na Flórida (EUA), causando severos danos em Ficus altissima, F. aurea, F. benjamina, F. lyrata, F. maclellandii e F. microcarpa usadas em arborização pública e cercas, e no condado de Miami, com desfolha intensa até a morte das plantas. Atualmente vem se espalhando pelas Américas já tendo sido assinalada em Porto Rico, Jamaica, Ilhas Cayman e agora no Brasil (JESUS et al., 2010).

A infestação severa por este inseto, o qual é limitante para o desenvolvimento das árvores da espécie Ficus, pode causar secamento seguido de morte das árvores. Entretanto, segundo o pesquisador Francsisco Zorzenon do Instituo

Mívia Rosa de Medeiros Vichiato et al. 
Biológico de São Paulo, a possibilidade da moscabranca-dos-fícus causar danos a pessoas e animais é mínima, o único perigo é o de alergia ocasionada pelo contato com os fungos das folhas caídas, para a pessoa com baixa resistência imunológica.

\subsection{Controle de Singhiella simplex}

Há ocorrência de controle biológico natural (inimigos naturais como os insetos Amitus bennetti, Curinus coerulensis, Encarsia protransvena e Exochomis childrei) - Velasco et al. 2011. Porém o alto nível de infestação por Singhiella simplex nos fícus belo-horizontinos não permite o controle natural da praga. A manutenção de inimigos naturais no ambiente urbano é importante estratégia de controle a longo prazo.

O controle químico para Singhiella simplex está sendo testado com inseticidas sistêmicos (neonicotinóides) aplicados no solo (MANNION, 2010; VELASCO et al., 2011). Entretanto, o controle químico de Singhiella simplex em áreas públicas brasileiras é de difícil aplicação, além da inexistência de produtos registrados, a localização, o porte e as condições de estresse dos indivíduos arbóreos dificultam a eficiência e a eficácia dos produtos (VELASCO et al., 2011).

\subsection{Indução de resistência dos fícus doentes / controle ecológico de Singhiella simplex}

Uma espécie exótica como Singhella simplex, nativa da Ásia, pode apresentar rápido aumento populacional, pois seus inimigos naturais são escassos. Plantas de fícus com queda expressiva de folha sugere que a mosca-branca-dos-fícus já passou por várias gerações, uma vez que o ciclo de vida deste inseto (ovo, ninfa e adulto) dura, aproximadamente, 30 dias (JESUS et al., 2010). Ao longo do tempo de estabelecimento, seu impacto é menor, quando preservados os inimigos naturais e, por isto, o uso de inseticidas deve ser planejado.

A indução de resistência de plantas é uma estratégia em potencial para prevenir ou, pelo menos, retardar as injúrias e danos de insetos na planta. O controle ecológico não se designa apenas ao combate da praga, mas também ao fortalecimento nutricional da planta de forma equilibrada (PRIMAVESI, 1994).

No manejo de doenças destaca-se o nutriente mineral silício que pode promover menor incidência de patógenos e aumento na proteção contra insetos fitófagos, pela formação de barreiras mecânicas e/ou alteração das respostas bioquímicas da planta ao ataque da praga, aumentando a síntese de toxinas que podem agir como substâncias inibidoras ou repelentes (DATNOFF et al., 2001; CAMARGO, 2007; POLANCZYK et al. 2008; SILVA et al., 2010).

Qualquer tipo de adubação que favoreça as condições fisiológicas da planta poderá conferir-lhe resistência, tendo em vista que ao fornecer-lhe os diversos nutrientes que lhe são necessários e nas proporções relativas às suas necessidades efetivas, mantêm-na em equilíbrio nutricional, possibilitando resistir mais aos ataques de agentes externos, como os insetos (SILVA et al., 2010)

Outro fator limitante do solo para árvores saudáveis é a compactação. A aeração do solo pode ser feita através de perfurações verticais até $50 \mathrm{~cm}$ de profundidade ou através de trincheiras radiais, ambas posteriormente preenchidas com material poroso. O efeito mais duradouro será obtido com a recuperação da biologia do solo, eliminado inicialmente o fator de compactação (normalmente pisoteio) e na sequência o solo é recoberto com material orgânico de granulometria grossa. Este material orgânico deverá ter uma espessura de no máximo $10 \mathrm{~cm}$. Outra alternativa é a cobertura com uma camada fina de solo $(5 \mathrm{~cm})$ com elevado teor de matéria orgânica e o estabelecimento de plantas de cobertura (para evitar o pisoteio).

A queda expressiva de folhas e morte progressiva de ramos dos fícus localizados no canteiro central da Avenida Bernardo Monteiro, em Belo Horizonte, Minas Gerais, Brasil, pode estar relacionada a fatores de estresse, que impedem o rebrotamento das folhas e a recuperação das árvores por restrição a água e nutrientes do solo. Além disso, as podas recentemente realizadas ou quedas de galhos podem ter aumentado o estresse dos exemplares, que ficaram mais suscetíveis à infestação das moscas. 
Os agentes causais da queda expressiva de folhas e da morte progressiva de ramos de F. microcarpa no canteiro central da Avenida Bernardo Monteiro em Belo Horizonte, Minas Gerais, Brasil são, respectivamente, a mosca-branca-dos-fícus ( $S$. simplex) e o fungo $L$. theobromae.
O controle do desfolhamento e da morte descendente em F. microcarpa ainda é um desafio e novos estudos deverão ser realizados, visando obter informações adicionais sobre o controle de $S$. simplex e L. theobromae em F. microcapa no Município.

\section{REFERÊNCIAS BIBLIOGRÁFICAS}

CAMARGO, J.M.M. Efeito da aplicação de silício e nitrogênio em plantas de Pinus taeda L. (Pinaceae) na performance do pulgão-gigante-dos-pinus - Cinara atlantica (Hemíptera: Aphididaea). Dissertação (Mestrado em Entomologia), Universidade Federal do Paraná, Curitiba, 2007. 102p.

CARDOSO, J.E.; VIANA, F.M.P.; BEZERRA, M.; SOUSA, T.R.M.; CYSNE, A Q.; FARIAS, F.C. Transmissão de Lasiodiplodia theobromae, agente da resinose, em propágulos de cajueiro. Boletim de pesquisa e desenvolvimento / Embrapa Agroindústria Tropical, 2009, 21p.

CASTRO, C.M. Mosca-branca é causa das mortes de árvores em SP. Folhas de São Paulo, São Paulo, $17 / 03 / 2011$.

DATNOFF, L.E.; SNYDER., G. H.; KORNDORFER G.H. Silicium in Agriculture, Amsterdam: Elsivier Science. 2001, p.424, v.8

DOMINGUES, R.J.; TÖFOLO, J.G.; FERRARI, J.T.; NOGUEIRA, E.M.C. Podridão da haste de Begonia elatior causada por Lasiodiplodia theobromae. Instituto Biológico, São Paulo, Documento Técnico 013, set. de 2011, p.1-8.

DUARTE, R.H. À sombra dos fícus: cidade e natureza em Belo Horizonte. Ambiente e Sociedade, Campinas, v. 10, n.2, p. 25-44, 2007.

FEITOSA, V.S.; PESSOA, M.N. G.; ALMEIDA, J.L.; SILVA, M.G.V. Efeito da tintura, extrato bruto e sumo de plantas medicinais sobre o crescimento micelial de Colletotrichum gloeosporioides, Lasiodiplodia theobromae e Macrophomina phaseolina "in vitro". Fitopatologia Brasileira, Brasília, v. 25 (Suplemento), p. 374. 2000 .

FREIRE, F.C.O.; VIANA, F.M.P.; CARDOSO. J.E.; SANTOS, A.A. Novos hospedeiros do fungo Lasiodiplodia theobromae no Estado do Ceará. Comunicado Técnico on Line N ${ }^{\circ}$ 91, Fortaleza, Ceará, 2004 (Disponível no site: http://www.cnpat.embrapa.br/cnpat/cd/jss/ acervo/ Ct-091.pdf).

JESUS, L.F. M; TRINDADAE, T.D.; FERREIRA-JR, A.J.; RACCA-FILHO, F.; LIMA, A.F. Registro de uma espécie exótica de mosca-branca-dos-fícus (Hemiptera: Aleyrodidae) e sua disseminação no Brasil. Resumo. In: XXIII Congresso Brasileiro de Entomologia, Natal, RN, 2010

LIMA, G.S.A.; SANT'ANA, A.E. G.; LOPEZ, A.M.Q. Efeito de extratos aquosos de bulbo de alho (Allium sativum) sobre a germinação e o crescimento micelial de Botryodiplodia theobromae (Pat.) "in vitro". Fitopatologia Brasileira, Brasília, v. 18 (Suplemento), p. 303, Agosto, 1993.

Mívia Rosa de Medeiros Vichiato et al. 
LINS, S.R.O ; ALVES, E.; OLIVEIRA, S.M.A. Estudos da interação Lasiodiplodia theobromae x mangueira e caracterização morfológica de isolados do patógeno. Acta Microscópica, v. 19, n. 3, 2010, pp. 221-231.

MANNION, C. Biology and population dynamic of the ficus white-fly - Singhiela simplex. Invasive Pest. UF/IFAS. Florida. Tropical Research and Education Center. 2010. 24p.

MOHALI, S.; BURGESS, T.I.; WINGFIELD, M.J. Diversity and host association of the tropical tree endophyte Lasiodiplodia theobromae revealed using simple sequence repeat markers. Forest Pathology, Blackwell Verlag, Berlin, v. 35, p. 385-396, 2005

PAZ-LIMA, M.L.; UESUGI, C.H.; SANTOS, G.R. Morte progressiva de ramos de Ficus benjamina causada por Phomopsis cinerescens nos Estados de Tocantins e Minas Gerais. Fitopatologia Brasileira, Brasília, v. 30, n.1, p. 9, 2005.

PEREIRA, A.V.S. Sensibilidade a fungicidas e adaptabilidade de Lasiodiplodia theobromae patogênico ao mamão. (Dissertação - Mestrado em Fitotecnia), Universidade Rural de Pernambuco, Recife, 2009, 57p.

PINHO, M.M.; MELO, F.A.B. ; MOURAO, A.E.B. ; PARENTE FILHO, E.G.; PARENTE, K.M.S. Controle do Trips Gynaikotrips ficorum (MARCHAL, 1908) em Ficus (Ficus benjamina Linneu, 1758 sob a ação da pimenta malagueta (Capsicum frutescens). In: XVI Encontro de Zoologia do Nordeste - EZN, 2007, Garanhuns. XVI Encontro de Zoologia do Nordeste, 2007.

POLANCZYK, R.A; PRATISSOLI, D; PAYE, H.S; PEREIRA, V.A; BARROS, F.L.S; OLIVEIRA, R.G.S; PASSOS, R.R.; MARTINS FILHO, S. 2008. Indução de resistência à Mosca minadora em crisântemo usando composto silicatado. Horticultura Brasileira, v. 26, n.1, p. 240-243, 2008.

PRIMAVESI, A. Manejo ecológico de pragas e doenças: técnicas alternativas para a produção agropecuária e defesa do meio ambiente, São Paulo; Nobel, 1994. 137 p.

RAM, C. Efeito de fungicidas aplicados em mistura sobre incidência da queima-das-folhas e produção do coqueiro. Fitopatologia Brasileira, Brasília, v. 18, n.1, p. 264, 1993.

RODRIGUES, R. Caracterização morfológica e patológica de Lasiodiplodia theobromae (Pat.) Griffon \& Maubl., agente causal das podridões de tronco e raízes da videira. Dissertação (Mestrado em Agricultura Tropical e Subtropical), Instituto Agronômico de Campinas, 53p. 2003.

SANTOS, A.A.; CARDOSO, J.E. \& FREIRE, F.C.O. Controle de Lasiodiplodia theobromae em frutos e sementes de gravioleira e de ateira. Fitopatologia Brasileira, Brasília, v. 25 (Suplemento), p. 456, Agosto, 2000 .

SILVA, M.; SOARES, M.A.; VIEIRA, G.T.; ZANUNCIO, J.C. Ataque de Gynaikothrips ficorum (Phlaeothripidae) em plantas Ficus bejamina (Moraceae) de área urbana. In: II Simpósio de Entomologia, 2010, Viçosa. II Simpósio de Entomologia, 2007.

SILVA, V.F.; MORAES, J.C.; MELO, B.A. Fontes de silício na indução de resistência a insetos-praga e no desenvolvimento de plantas de batata inglesa. Revista Brasileira de Agroecologia, v. 05, n.02, p. 149-156, 2010 . 
VELASCO, G.D.N.; MOURA, R.G.; BERTI-FILHO, E.; COUTO, H.T.Z. Avaliação da infestação por Singhiella simplex (Hemíptera: Aleyrodidae) em Ficus benjamina no município de São Paulo - SP, Brasil. Revista de Agricultura, São Paulo, v.86, n.2, p. 134-141, 2011.

ZAMBOLIM, L.; COSTA, H; VENTURA, J.A.; VALE, F.X.R. Controle de doenças em pós-colheita de frutas tropicais. In: Manejo integrado de doenças e pragas de fruteiras tropicais. ZAMBOLIM, L. (ed.), cap. 12, v. 2, p. 443-500. 2002. 